\title{
SYNDROMIC SURVEILLANCE: THE NEXT PHASE OF PUBLIC HEALTH MONITORING DURING THE H1N1 INFLUENZA PANDEMIC?
}

A J Elliot (alex.elliot@hpa.org.uk) ${ }^{1}$

1. Real-time Syndromic Surveillance Team, Health Protection Agency West Midlands, Birmingham, United Kingdom

This article was published on 5 November 2009.

Citation style for this article: Elliot AJ. Syndromic surveillance: the next phase of public health monitoring during the H1N1 influenza pandemic?. Euro Surveill. 2009;14(44):pii=19391. Available online: http://www.eurosurveillance.org/ViewArticle.aspx?ArticleId=19391

In this edition of Eurosurveillance, Coory and colleagues describe the use of a deputising medical service for influenza-like illness (ILI) surveillance in Australia [1]. They validate these novel surveillance data against a traditional general practitioner (GP) sentinel network. The use of sentinel GP surveillance networks is considered the gold standard of influenza surveillance in many European countries and formed the basis of the European Influenza Surveillance Scheme (EISS), which tracked seasonal influenza across 30 European countries from 1996 to 2008 [2]. Coory et al. demonstrate that the data collected from the deputising medical service were comparable with the sentinel GP data, thus illustrating the potential of these novel surveillance data to track influenza.

We are now in the midst of the first influenza pandemic the world has experienced for over 40 years. The pandemic influenza $A(H 1 N 1) v$ virus spread surprisingly quickly: the initial cases detected in North America and Mexico during the first few weeks of April 2009 [3,4] were quickly followed by detection in other countries, and by the end of April, the virus had spread to over 123 countries. To date (25 October 2009), it is estimated that there have been over 440,000 laboratory-confirmed cases [5]. Despite initial fears regarding the relatively high mortality rate in Mexico, the pandemic H1N1 influenza infection has so far generally presented with relatively mild acute respiratory symptoms. During the early stages of the pandemic the majority of deaths occurred in the Americas, with the only other recorded deaths in Australia, the Philippines, Spain, Thailand and the United Kingdom (UK) [6]. Currently (25 October 2009), the estimated number of deaths is at least 5,700; these deaths now are more widespread across the globe, however the main burden still lies in the Americas [5].

There are several ways of tracking the spread of influenza and estimating the burden of disease within the community. Monitoring confirmed laboratory reports, GP-diagnosed episodes of disease, emergency department (ED) attendances, hospital admissions and excess deaths are all methods employed by public health authorities. Laboratory-confirmed case reporting of influenza was used to track the initial pandemic H1N1 influenza cases during the first months of the outbreak. However, in some countries the number of cases then increased markedly, resulting in a change of policy from 'containment' to 'treatment'. In these situations, the large number of cases makes it impractical to use laboratory testing to confirm each case and therefore, the use of syndromic surveillance takes precedence as the primary means of estimating the community burden of pandemic influenza infections.

The origins of the recent increase in the use of syndromic surveillance can be traced to the United States (US), where the use of data from secondary healthcare facilities for sentinel surveillance is relatively common (though few systems are national). The response to the threat from (bio)terrorist activities since the events on 11 September 2001 has increased the frequency of such systems which are now common in individual states [7-10]. One of the first syndromic surveillance systems to evolve from the anti-terrorist response started in New York City, where ED patient attendances with 'chief complaints' are monitored on a daily basis [11].

Although the US have been the main focus of syndromic surveillance (predominantly ED systems), other international groups have developed similar systems, now including the current paper by Coory et al. in this edition of Eurosurveillance [1]. A French syndromic surveillance system (Oscour ${ }^{\circledR}$ ) was developed in response to the European heatwave in summer 2003 [12]. Amongst a range of infections, this system has been utilised to monitor influenza and norovirus activity, and has also been used to report on potential heatwave-related morbidity in France [13]. Although the main focus of these systems has concentrated on monitoring respiratory $[13,14]$ and gastrointestinal infections [15-17], the systems have in some cases included linkages with mortality data [13].

In the UK, a combination of sentinel GP surveillance and data from telephone-health lines comprise the current national syndromic surveillance capability, although it is hoped that this will be expanded to use other sources such as ED attendances and GP out-of-hours provisions. Sentinel GP networks have been in operation for over 40 years in the UK: the Royal College of General Practitioners (RCGP) Weekly Returns Service (WRS) has provided continuous weekly reporting of GP-diagnosed ILI incidence rates in England and Wales since 1967 and monitored the 1968-1969 influenza pandemic which impacted on the UK during the winter 1969-1970 [18]. QSurveillance $®$ is a UK-based GP system that, since 2005, operates on a larger scale (in terms of both geographic coverage and patient population) compared to the RCGP WRS [19]. NHS Direct is a nurse-led telephone helpline run by the National Health Service (NHS) in England 
and designed to triage callers based on presentation of symptoms [20]. The syndromic surveillance system operated by NHS Direct and the Health Protection Agency (HPA) uses these symptombased telephone call data to provide real-time daily monitoring of influenza, and other seasonally occurring communicable diseases such as norovirus infections $[21,22]$. The main advantage of these systems is the provision of data in real-time, i.e. daily reports, thus providing a much more responsive surveillance system which allows early warning of potential problems. All NHS Direct data can be aggregated into specific age bands and broken down by region (including postcode analysis), which enables recognition of potential regional hot spots that might not be detected using traditional methods [23].

In the UK, there are surveillance programmes that undertake the integration of microbiological investigation into syndromic surveillance systems. Since 1992, the RCGP WRS sentinel GP system has, in collaboration with the HPA, undertaken virological investigation of a sample of patients diagnosed with ILI [24]. Results from this scheme are vital in providing the earliest community-based influenza virus isolations during an influenza season, providing information on the circulating influenza virus types/subtypes, potential virus-vaccine mismatch, vaccine effectiveness and the emergence of antiviral resistance. In addition, community-based respiratory samples from this system have been used retrospectively to assess the impact of newly discovered pathogens, e.g. human metapneumovirus [25]. In recent years the NHS Direct/HPA syndromic surveillance system has also been used to obtain clinical samples from patients calling the helpline. The novel aspect of this system is the self-sampling protocol which involves sending swabbing kits to patients who then take nasal swabs themselves and return the samples to a central laboratory [26]. Results from this pilot study were encouraging, and this has now been rolled out in the current pandemic situation in England to assess the frequency of community-based pandemic H1N1 influenza infections [27].

A potential disadvantage of using syndromic surveillance systems is the lack of specificity of the data collected. Laboratory reporting of confirmed cases provides an accurate representation of how many cases are positive for the pathogen of interest. Syndromic surveillance monitors disease patterns using syndromic indicators, which are primarily based upon clinically diagnosed (but not confirmed) episodes or symptom presentation. However, previous work has shown that despite these limitations, syndromic data can be extremely sensitive to community-based infections and act as potential early warning of imminent problems. This 'broad brush' approach of using non-specific indicators may capture patients who do not specifically meet the case definition, e.g. ILI. Experience from using the NHS Direct/HPA syndromic surveillance system has demonstrated that calls for 'fever' in children aged between five and 14 years can be used as an early warning indicator of influenza activity [28]. Fever calls in this age group are sensitive to increasing community-based influenza activity, thus demonstrating that using an indicator that is not based upon a range of presenting symptoms associated with influenza can be reliably used to monitor influenza activity [28].

Another potential disadvantage of syndromic surveillance is the impact of media reporting. In situations such as the outbreak of severe acute respiratory syndrome (SARS) in 2003, and the current H1N1 influenza pandemic, the mass media reporting on these events can cause anxiety amongst the population. This can prompt symptomatic patients, who would normally have self-treated their symptoms, to seek healthcare advice such as a GP consultation or a call to NHS Direct. It is therefore very difficult to disentangle the effects of media reporting from the true burden of infection in the community, and without laboratory reporting it is not possible to estimate the proportion of true positives.

Syndromic surveillance constitutes the use of data systems that do not rely on confirmatory laboratory testing of patient samples. In principle, the data used in syndromic surveillance are primarily collected for other purposes, e.g. clinical management of patients. The general advantage of these systems is the provision of data that are timelier than traditional laboratory reporting, i.e. 'real-time'. In most cases, fewer resources are required to maintain the systems. They also have the potential to cover a greater range of disease indicators and therefore can be used to monitor many different scenarios within public health protection. This also includes the surveillance of non-infectious public health issues such as bioterrorist threat, chemical incidents, natural phenomena such as heatwaves or flooding, and mass gathering events, for instance the Olympic Games.

In recent years, there have been moves to utilise the massive potential of the internet for surveillance purposes. The health information seeking behaviour of the population has now changed with the wealth of online help available: in response, Google.org has released Google Flu Trends, a system that monitors influenzabased search queries from the Google search engine. Analyses of data collected from the US were modelled using CDC sentinel GP surveillance data with remarkably high correlation between the two data series [29]. This work has now been transposed to a publicly accessible website that uses this system to monitor regional influenza activity in the US, and has more recently expanded to cover Australia, New Zealand, Mexico and Europe [30,31]. In this week's issue of Eurosurveillance, Wilson et al. present a rapid communication comparing results from Google Flu Trends with data from existing surveillance systems in New Zealand [32].

The continuing advancement of syndromic surveillance is providing further public health monitoring of infectious diseases, and in particular influenza. Novel systems such as internet-based search queries are providing a new aspect to the established systems and thus providing another piece of the syndromic surveillance jigsaw.

\section{References}

1. Coory M, Grant K, Kelly H. Influenza-like illness surveillance using deputising medical service corresponds to surveillance from sentinel general practices. Eurosurveillance 2009;14(44):pii=19387. Available from: http://www. eurosurveillance.org/ViewArticle.aspx?ArticleId=19387

2. Arkema JM, Meijer A, Meerhoff TJ, Van Der Velden J, Paget WJ. Epidemiological and virological assessment of influenza activity in Europe, during the 20062007 winter. Euro Surveill 2008;13(34). pii: 18958. Available from: http://www. eurosurveillance.org/ViewArticle.aspx?ArticleId=18958

3. Centres for Disease Control and Prevention (CDC). Outbreak of swine-origin influenza A (H1N1) virus infection - Mexico, March-April 2009. MMWR Morb Mortal Wkly Rep 2009;58(17):467-70. Available from: http://www.cdc.gov/mmwr/ preview/mmwrhtml/mm58d0430a2.htm

4. Centers for Disease Control and Prevention (CDC). Swine influenza A (H1N1) infection in two children--Southern California, March-April 2009. MMWR Morb Mortal Wkly Rep 2009;58(15):400-2. Available from: http://www.cdc.gov/mmwr/ preview/mmwrhtml/mm5815a5.htm 
5. World Health Organization. Pandemic (H1N1) 2009 - update 69. 2009 [12 October 2009]; Available from: http://www.who.int/csr/don/2009_10_09/en/index.html

6. World Health Organization. Pandemic (H1N1) 2009 - update 56. 2009 [12 0ctober 2009]; Available from: http://www.who.int/csr/don/2009_07_01a/en/index.html

7. Centers for Disease Control and Prevention (CDC). Injury and illness surveillance in hospitals and acute-care facilities after Hurricanes Katrina And Rita--New Orleans area, Louisiana, September 25-October 15, 2005. MMWR Morb Mortal Wkly Rep 2006;55(2):35-8. Available from: http://www.cdc.gov/ mmwr/preview/mmwrhtml/mm5502a4.htm

8. Hadler JL, Siniscalchi A, Dembek Z. Hospital admissions syndromic surveillance--Connecticut, October 2001-June 2004. MMWR Morb Mortal Wkly Rep 2005;54 Suppl:169-73. Available from: http://www.cdc.gov/mmwr/preview/ mmwrhtml/su5401a27.htm

9. Travers D, Barnett C, Ising A, Waller A. Timeliness of emergency department diagnoses for syndromic surveillance. AMIA Annual Symposium proceedings. AMIA Annu Symp Proc. 2006:769-73.

10. Yuan CM, Love S, Wilson M. Syndromic surveillance at hospital emergency departments--southeastern Virginia. MMWR Morb Mortal Wkly Rep 2004;53 Suppl:56-8. Available from: http://www.cdc.gov/mmwr/preview/mmwrhtml/ su5301a14.htm

11. Heffernan R, Mostashari F, Das D, Karpati A, Kulldorff M, Weiss D. Syndromic surveillance in public health practice, New York City. Emerg Infect Dis. 2004;10(5):858-64.

12. Josseran L, Caillere N, Brun-Ney D, Rottner J, Filleul L, Brucker G, et al. Syndromic surveillance and heat wave morbidity: a pilot study based on emergency departments in France. BMC Med Inform Decis Mak. 2009;9:14.

13. Josseran L, Nicolau J, Caillere N, Astagneau P, Brucker G. Syndromic surveillance based on emergency department activity and crude mortality: two examples. Euro Surveill. 2006;11(12):225-9. Available from: http://www. eurosurveillance.org/ViewArticle.aspx?ArticleId $=668$

14. Kawana A, Teruya K, Kirikae T, Sekiguchi J, Kato Y, Kuroda E, et al. "Syndromic surveillance within a hospital" for the early detection of a nosocomial outbreak of acute respiratory infection. Jpn J Infect Dis. 2006;59(6):377-9.

15. Chen KT, Chen PY, Tang RB, Huang YF, Lee PI, Yang JY, et al. Sentinel hospital surveillance for rotavirus diarrhea in Taiwan, 2001-2003. J Infect Dis. 2005;192 Suppl 1:S44-8.

16. Fang ZY, Wang B, Kilgore PE, Bresee JS, Zhang LJ, Sun LW, et al. Sentinel hospital surveillance for rotavirus diarrhea in the People's Republic of China, August 2001-July 2003. J Infect Dis. 2005;192 Suppl 1:S94-9.

17. Moore KM, Edgar BL, McGuinness D. Implementation of an automated, real-time public health surveillance system linking emergency departments and health units: rationale and methodology. CJEM. 2008;10(2):114-9.

18. Elliot AJ, Fleming DM. Surveillance of influenza-like illness in England and Wales during 1966-2006. Euro Surveill. 2006;11(10):249-50. Available from: http://www.eurosurveillance.org/ViewArticle.aspx?ArticleId=651

19. Health Protection Agency/Nottingham University Division of Primary Care. QSurveillance ${ }^{\circledR}$ National Surveillance System Weekly Bulletin. 2009 [12 October 2009]; Available from: http://www.hpa.org.uk/hpr/infections/primarycare.htm

20. Baker M, Smith GE, Cooper D, Verlander NQ, Chinemana F, Cotterill S, et al. Early warning and NHS Direct: a role in community surveillance? J Public Health Med. 2003;25(4):362-8.

21. Cooper DL, Smith GE, Hollyoak VA, Joseph CA, Johnson L, Chaloner R. Use of NHS Direct calls for surveillance of influenza--a second year's experience. Commun Dis Public Health. 2002;5(2):127-31.

22. Cooper DL, Smith GE, O'Brien SJ, Hollyoak VA, Baker M. What can analysis of calls to NHS direct tell us about the epidemiology of gastrointestinal infections in the community? J Infect. 2003;46(2):101-5.

23. Cooper DL, Verlander NQ, Smith GE, Charlett A, Gerard E, Willocks L, et al Can syndromic surveillance data detect local outbreaks of communicable disease? A model using a historical cryptosporidiosis outbreak. Epidemiol Infect. 2006;134(1):13-20.

24. Fleming DM, Chakraverty P, Sadler C, Litton P. Combined clinical and virological surveillance of influenza in winters of 1992 and 1993-4. BMJ. 1995;311(7000):290-1.

25. Stockton J, Stephenson I, Fleming D, Zambon M. Human metapneumovirus as a cause of community-acquired respiratory illness. Emerg Infect Dis. 2002;8(9):897-901.

26. Cooper DL, Smith GE, Chinemana F, Joseph C, Loveridge P, Sebastionpillai P, et al. Linking syndromic surveillance with virological self-sampling. Epidemiol Infect. 2008;136(2):222-4.

27. Elliot AJ, Powers C, Thornton A, Obi C, Hill C, Simms I, et al. Monitoring the emergence of community transmission of influenza A/H1N1 2009 in England: a cross sectional opportunistic survey of self sampled telephone callers to NHS Direct. BMJ. 2009;339:b3403.

28. Cooper DL, Verlander NQ, Elliot AJ, Joseph CA, Smith GE. Can syndromic thresholds provide early warning of national influenza outbreaks? J Public Health (0xf). 2009;31(1):17-25.
29. Ginsberg J, Mohebbi MH, Patel RS, Brammer L, Smolinski MS, Brilliant L. Detecting influenza epidemics using search engine query data. Nature. 2009;457(7232):1012-4.

30. Eurosurveillance editorial team. Google Flu Trends includes 14 European countries . Euro Surveill. 2009;14(40):pii=19352. Available online: http://www. eurosurveillance.org/ViewArticle.aspx?ArticleId=19352

31. Google flu trends. Homepage on the internet. Google.org; 2009. Available from: http://www.google.org/flutrends/.

32. Wilson N, Mason K, Tobias M, Peacey M, Huang QS, Baker M. Interpreting "Google Flu Trends" data for pandemic H1N1 influenza: The New Zealand experience. Euro Surveill. 2009;14(44):pii=19386. Available from: http://www. eurosurveillance.org/ViewArticle.aspx?ArticleId=19386 